\title{
Family Support and Adherence to Treatment in Patients Diagnosed with Schizophrenia in Tabasco, Mexico: A Case- Series Study
}

Homero Daniel Hernandez-Yánez ${ }^{1}$, Jorge E Reyes-Tovilla', Isela E Juárez-Rojop, Thelma Beatriz González-Castro², Mario Villar-Soto ${ }^{1}$, María Lilia López-Narváez ${ }^{4}$, Humberto Nicolini ${ }^{5}$, Alma Genis ${ }^{5}$ and Carlos Alfonso Tovilla-Zárate ${ }^{6 *}$

${ }^{1}$ University Juarez Autonoma de Tabasco, Academic Division of Health Sciences, Villahermosa, Tabasco, Mexico

${ }^{2}$ University Juarez Autonoma de Tabasco, Multidisciplinary Academic Division of Jalpa de Mendez, Cunduacán, Tabasco, Mexico

${ }^{3}$ Department of Psychiatry, High Specialty Hospital Gustavo A. Rovirosa Pérez, Ministry of Health, Villahermosa, Tabasco, Mexico

${ }^{4}$ Yajalón General Hospital, Ministry of Health, Yajalón, Chiapas, Mexico

${ }^{5}$ National Instituto of Genomic Medicine (INMEGEN), Psychiatric Care Services (SAP), Ministry of Health, Mexico City, Mexico

${ }^{6}$ Universidad Juarez Autonoma de Tabasco, Comalcalco Multidisciplinary Academic Division, Comalcalco, Tabasco, Mexico

\begin{abstract}
Schizophrenia is a severe mental illness that affects adults, especially between 15 to 35 years of age. Patients with schizophrenia have difficulty looking after themselves, completing their studies, holding a job, or being part of their community. In Mexico, there are mental health programs that provide help and assistance to people with mental health problems, but given the country's current socioeconomic instability, a shortage of medication exists, as well as a deficit in trained personnel and mental health professionals, plus a lack of a public education program to prevent discrimination against people with mental disorders. Unfortunately, the exact number of people suffering from schizophrenia in developing countries (including Mexico) is unknown, since there are no recent censuses in mental health. Literature about schizophrenia mentions genetic predisposition and environmental factors. In this article, we showed 4 patients with schizophrenia who were treated at the Regional Hospital of High Specialty in Mental Health (Hospital Regional de Alta Especialidad en Salud Mental, HRAESM, in Spanish). Our main objective was the identification of symptoms in our patients and to compare the medication and side effects due to treatment in these patients. Substance abuse, dysfunctional family and family history of mental illness were characteristics associated with our patients, as well as side effects. However, the implementation of more studies is necessary to understand the risk factors associated with schizophrenia in our population.
\end{abstract}

Keywords: Schizophrenia; Risk factors; Family environment; C report; Side effects

\section{Background}

In general, schizophrenic disorders are characterized by fundamental and characteristic distortions of thought and perception, as well as inappropriate or blunted affects [1]. Schizophrenic patients also experience hallucinations and delusions (referred to as "positive" symptoms) and a variety of other symptoms including decreased social function and speech, flat affect, disorganized thought and low motivation (referred to as "negative" symptoms). Cognitive impairment is also a core feature of schizophrenia [2]. This condition most commonly starts during adolescence, with prevalence rates reaching $1 \%$ of the total population $[3,4]$. Nevertheless, the prevalence in other studies goes from 2.7 to 8.2 cases per 1000 people [5]. Recent studies suggest that males have a higher lifetime risk for schizophrenia than females (1:3). The incidence peak for males and females is in the decade between 15 and 24 years of age. The peak for young adults is more marked in males; however, females have a second peak within the range 55-64 years old [5,6]. In Mexico, the range of prevalence is 20 cases per 1000 people [6,7]. The medical history, risk factors and the onset characteristics of schizophrenia are variable. For instance, Ciompi et al. mentions that $50 \%$ of patients show long prodromes, whereas $50 \%$ present acute onsets [8]. Other studies suggest a large list of signs, symptoms, and behaviors (poor social adjustment, poor attention skills, lower IQ, among others). However, the symptomatic course has an unpredictable pattern with partial or full remissions followed by recurrences $[5,9]$.

Studies from the northern and southern hemispheres suggest that, although the risk is small, individuals with schizophrenia are born more often during the winter than in the summer [10,11]. With regard to genetic susceptibility, several genes have been suggested to convey susceptibility to schizophrenia [12-14]. According to this hypothesis, the neuregulin 1(NGR-1) gene is considered a main candidate due to its altered expression in this illness. In addition, neuregulin 1 has been involved in the regulation of glutamate and dopamine neurotransmitter systems (both relevant in the disease process). Finally, neuregulin lis located on chromosome $8 \mathrm{p}$, which has been associated with schizophrenia itself [15]. Furthermore, other studies mention NGR-1 as a candidate gene because of the schizophrenia-like phenotype seen in mutant mice [16].

In this part of the globe, there are no academic reports that include patients with schizophrenia. However, since this region in Mexico was selected to participate as part of the Genomic Psychiatry Cohort (GPC) [17] it was necessary to select patients with schizophrenia living in Mexico (our cases come from Tabasco, Mexico). To be consistent with the international guidelines it is necessary the identification of characteristics presented by our patients and the comparison of the drugs internationally suggested in the treatment of schizophrenia with the ones provided in Mexico. To reach a schizophrenia diagnosis in the

*Corresponding author: Carlos Alfonso Tovilla Zárate, Universidad Juárez Autónoma de Tabasco, División Académica Multidisciplinaria de Comalcalco Ranchería Sur, Cuarta Sección, C.P. 86650, Comalcalco, Tabasco, México, Tel: 52 9933581500; E-mail: alfonso tovillaz@yahoo.com.mx

Received April 07, 2015; Accepted May 31, 2015; Published June 07, 2015

Citation: Hernandez-Yánez HD, Reyes-Tovilla JE, Juárez-Rojop IE, GonzálezCastro TB, Villar-Soto M, et al. (2015) Family Support and Adherence to Treatment in Patients Diagnosed with Schizophrenia in Tabasco, Mexico: A Case- Series Study. J Psychiatry 18: 304 doi: 10.4172/2378-5756.1000304

Copyright: (c) 2015 Hernandez-Yánez HD, et al. This is an open-access article distributed under the terms of the Creative Commons Attribution License, which permits unrestricted use, distribution, and reproduction in any medium, provided the original author and source are credited 
Citation: Hernandez-Yánez HD, Reyes-Tovilla JE, Juárez-Rojop IE, González-Castro TB, Villar-Soto M, et al. (2015) Family Support and Adherence to Treatment in Patients Diagnosed with Schizophrenia in Tabasco, Mexico: A Case- Series Study. J Psychiatry 18: 304 doi: 10.4172/23785756.1000304

Page 2 of 4

"Hospital Regional de Alta Especialidad en Salud Mental" (HRAESM, initials in Spanish), 6 criteria (A-F) of the Diagnostic and Statistical Manual of Mental Disorders was used [18]. We contacted 15 patients of which 4 individuals agreed to participate $(26.66 \%), 3$ were not living in the southeast of Mexico anymore (20\%) and 8 people decline to participate $(53.33 \%)$. The authors reported 4 cases with schizophrenia diagnosis that were jointly managed by the medical and the mental health teams in the medical wards and outpatient care unit of the HRAESM and the "Hospital Regional de Alta Especialidad Dr. Juan Graham Casasús" (HRAEJGC, initials in Spanish) between March 2013 and June 2014.

\section{Case Presentation}

\section{Case 1}

G. L. is a 20-year-old unmarried, unemployed male, with no family history of mental illness. During the interview, the patient admitted to drug abuse (cannabis and amphetamines), alcohol and tobacco for more than two years, without traumatic experiences. He lives with both of his parents and his younger sister, with adequate shelter. His father drinks, uses marihuana and physically abuses his mother, although he quitted alcohol and cannabis for over 2 years (these characteristics qualify this household as a dysfunctional family). When the patient was 3 years old, he presented tonic-clonic seizures caused by a fever. In July 2013, at the age of 18, he presented soliloquy, disorganize speech, verbiage, inappropriate laughter and insomnia, together with auditory hallucination and somatic delusion. Three months later he presented catatonic behavior, social withdrawal, social/occupational dysfunction that led him to dangerous situations (he started fighting with random people on the street), delusion of reference "the neighbors said that I am a thief and when they see me they start talking bad things of me (sic)". He was admitted to the outpatient clinic of the HRAESM where the patient was counseled and started a treatment with risperidone and haloperidol p.o. Three months later, the patient presented an extrapyramidal symptom caused by risperidone and was admitted to the emergency unit of the HRAEJGC. A computerized tomography (CT) was performed and an arachnoid cyst was found. The neurology department evaluated the CT scan and reported that the arachnoid cyst did not represent any risk or had clinical relevance, but he received followed-up in the outpatient care. During his hospital stay, he was treated with biperiden until the extrapyramidal side effects (EPSE) were resolved. The HRAESM transferred the patient to the HRAEJGC outpatient care.

Currently, he attends regular psychiatric and neurologic sessions at the HRAEJGC. After he was diagnosed with schizophrenia, he started treatment with quetiapine, clonazepam and biperiden tablets. He was visited at his home and was reported to be stable on medications, although he continues consuming cannabis and alcohol. The family has had some economic problems, causing him to neglect his medical consultation on the outpatient care. Nevertheless, the family is supporting the patient's recovery. The authors consider that the patient has a good family environment. During the mental status exam he was wearing good, clean cloths, rapport without difficulties, neutral mood, normal affect, clear content of speech although accompanied with irrational laughs, and logical coherence of thought. Insight was present.

\section{Case 2}

K. Y. is an 18-year-old, unmarried, unemployed female. She denied being on drugs, tobacco or alcohol; without traumatic experiences or family dysfunction. She is living with both of her aged parents and her older sisters with adequate shelter. Her grandmother had similar symptoms but was not diagnosed by a mental health professional. She was admitted to the outpatient care of the HRAESM at the age of 12, when she was diagnosed with paranoid schizophrenia. She presented negative symptoms for 8 months (such as abolition). In addition, she presented anhedonia and social/occupational dysfunction (she had to change schools after fighting with her classmates). One month later, the prodromal symptoms started; 2 months later, she left school. During the next months, she presented bizarre delusions, such as: "the sun is killing my skin by putting x-rays under it (sic)", delusion of reference: "people see me with anger and they want to hurt me (sic)", somatic delusion, mood-congruent delusion: "the news anchors on television threat me (sic)". She also manifested visual, auditory and olfactory hallucinations: "when I go to the bathroom a witch dressed like a clown wants me to follow her and she smells like burnt skin (sic)". She engaged in deliberated self-harm with suicidal behavior in one occasion. The patient was counseled and started with daily doses of risperidone $(4 \mathrm{mg})$ and olanzapine $(10 \mathrm{mg})$ p.o. Regular psychiatric, psychological and family therapy sessions commenced after the paranoid schizophrenia diagnosis was made. Three months later the patient showed remarkable improvements in her mental state. She has been successfully treated for a 6 -month period without prodromal or residual symptoms. She lives in a good family environment, with her sisters and parents involved in strengthening the treatment. She attends the outpatient clinic on appointment days and has been stable on medications. During the mental status exam she was wearing clean clothes; rapport without difficulties, neutral mood and normal affect, with clear content of speech, logical coherence of thought content and process. Insight was present.

\section{Case 3}

R.M. is a 33-year-old, unmarried, unemployed male. He is living with his aged parents with adequate shelter. He has a record of mental illness in his family: one of his uncles (brother of his father) was diagnosed with schizophrenia. He is not known as diabetic or hypertensive. The patient's mother admitted abuse of alcohol and tobacco for more than ten years on the part of her son. He started with prodromal symptoms, delusion of reference, persecutory delusion, social withdrawal and visual and auditory hallucinations since 2004. Six months later he started with irritability and attacked his mother every time she tried to interact with him. During the next days he presented psychotic symptoms and was taken to the HRAESM where he was hospitalized for control and observation. In the next days he was diagnosed with schizophrenia and started treatment with risperidone and olanzapine. After 2 weeks of admission, he left the ward with his parents and return 1 month later presenting another episode of psychosis because he was not taking the medication properly. The mother was interviewed and reported that the patient presented continuous states of irritability, hostility, poor insight and refused to take the medications saying: "I am not sick, I do not need those pills, you want to kill me (sic)". He also presented soliloquy, delusion of reference, persecutory delusion, and catatonia condition. He was admitted to the psychiatric ward of the HRAESM where intramuscular risperidone and olanzapine were given. One month after his admission he left the ward to an unknown destination with his parents. The patient was counseled and started with psychiatric and family therapy sessions; however, he only assisted to one. His mother was interviewed once again and revealed that she had had to hide the medication in his food in order to continue the treatment, she reported an improvement in his mental state, but 4 days later the patient left home and went missing for 3 days. When he arrived home he presented grossly disorganized behavior, irritability, 
Citation: Hernandez-Yánez HD, Reyes-Tovilla JE, Juárez-Rojop IE, González-Castro TB, Villar-Soto M, et al. (2015) Family Support and Adherence to Treatment in Patients Diagnosed with Schizophrenia in Tabasco, Mexico: A Case- Series Study. J Psychiatry 18: 304 doi: 10.4172/23785756.1000304

Page 3 of 4

insomnia and was drunk. His mother called the mental health team for help and reported that the patient had walked around the city during the days he disappeared and on the last day he had stabbed random people in the neck without any reason, leaving four persons severely wounded.

The injured people were treated at the emergency unit of the HRAEJGC and were reported to be out of danger.

\section{Case 4}

M.T. is a 44-year-old, divorced, unemployed female. She lives with her two sons and aged parents in a regular family environment, she receives socioeconomic support from her mother and sons, but her husband left her. She has no record of mental illness in her family; her father has diabetes mellitus. She has been diagnosed with type 2 diabetes mellitus (DM). She used to have good social pre-morbid adaptation, good relations with her husband and family. Medical history revealed a traumatic experience: when she was 26-years-old she witnessed a pipeline explosion near her home, which burned and destroyed everything in a radius of 16 acres, causing her insomnia during 1 month. At the aged of 27 , she started to suffer prodromal symptoms such as insomnia, dysphonia, irritability, soliloquy, social withdrawal, and anorexia. During the first 5 years of symptoms she was taken with shamans, witches and used phytotherapy. However, she developed personality deterioration, social/occupational dysfunction (causing her divorce), anhedonia, hostile and disorganized behavior, flattening, and reference and persecutory delusions. She arrived at the HRAESM when she presented an episode of psychosis and was taken to the medical center. The health professional administered intravenous diazepam and then was transferred to the HRAESM. She was admitted to the psychiatric ward and was diagnosed with paranoid schizophrenia; there she started treatment with clonazepam and olanzapine. After 3 weeks she left the ward and was counseled to attend psychiatric sessions at the outpatient care of the HRAESM. Nowadays, she continues with residual symptoms, she was interviewed at her house by the mental health team. During the mental status exam she was wearing dirty clothes and showed bad hygiene, difficult rapport (hostile, suspicious, uncooperative), catatonic behavior, avoided eye contact, blunted affect, with good rhythm and prosody of speech, persecutory delusion, and delusion of reference. In addition, she experienced perceptual disturbances (auditory allusions).

\section{Discussion}

In this study, we first showed the characteristics of the patients. The cases suggest that the environmental factors found in our patients were very similar to the risk factors described in the literature. In case 1 we found several risk factors such as: childhood trauma, substance abuse and dysfunctional family. In case 4 , the patient experienced a very stressful situation just before the onset of symptoms. In cases 2 and 3 , the authors found a family history of mental illness (though in case 3 the patient's relative was never diagnosed). These observed factors are consistent with those described in the literature. Among them, environmental components play a key role in the development of this condition $[19,20]$. Some of these components are stressrelated events such as migration to urban are $[21,22]$, cannabis use and childhood trauma $[23,24]$. However, other factors which also participate in the etiology of schizophrenia are of a genetic nature. In addition, we compared the drugs internationally suggested to treat schizophrenia with the ones provided in Mexico. In this regard, the primary treatment of schizophrenia and other schizophrenia spectrum disorders is antipsychotic medication. Within a limited range of effectiveness, olanzapine appears to be more effective than other drugs studied. Also, there were no significant differences in effectiveness between the conventional drugs (first-generation) and other secondgeneration drugs $[25,26]$.

It has been observed that patients that take antipsychotics have a higher rate of incidence of diabetes mellitus and metabolic syndrome, which may be a result of the medication together with a maladaptive lifestyle [27]. It is estimated that approximately $50 \%$ of patients treated with high-potency first- generation antipsychotics (such as haloperidol) develop acute extrapyramidal symptom within the first several days of treatment [28]. The likelihood of causing extrapyramidal symptom with second-generation antipsychotics also exists and depends on many factors, viz.: characteristics of the patient (age, gender, and concomitant conditions), history of the disease, previous treatment, choice of a particular antipsychotic, dose, duration of treatment, and adjuvant therapy $[29,30]$. Therefore, all these elements must be taken into consideration to minimize the risk of extrapyramidal symptoms and provide the best quality of care [29]. One of our patient's presented extrapyramidal side effects (EPSE) due to the use of antipsychotics. Other patient with long-term treatment of antipsychotics manifested DM, though the authors cannot assure that it was caused by the antipsychotics. Therefore, the follow-up sessions with a multidisciplinary approach should include the participation of the Internal Medicine and Clinical Nutrition Departments to ensure a better recovery and the prevention of side effects. Finally, we found that all cases presented in this study had good family support (participation of the parents, siblings and sons) in the assistance of the mentally ill patient. We observed a good adherence to treatment plus good family support which provide better outcome and prognosis. This is in agreement with other reports in the literature that have demonstrated that a combination of family support and knowledge of the disease help families and persons with schizophrenia to lessen the relapse frequency and improve compliance with the treatment $[31,32]$.

In summary, the results in this study provide evidence that the characteristics presented by our patients are in accordance with the ones found in the literature. Also, the presence of side effects and type 2 diabetes mellitus were observed in this Mexican population. This evidence shows that the population of the state of Tabasco may be considered in future studies regarding the efforts of clinic and experimental research.

\section{Conflict of Interest}

The authors declare not to have any competing interests.

\section{Acknowledgements}

The authors acknowledge the support from the Genomic Psychiatry Cohort Consortium (GPCC), together with NIH grants No. MH085548 and MH085542, as well as grant sponsors: Stanley Center for Psychiatric Research and Broad Institute of MIT and Harvard (Humberto Nicolini acts as the representative member in Mexico).

\section{References}

1. Organization WH (1992) The ICD-10 classification of mental and behavioura disorders. In: Clinical descriptions and diagnostic guidelines, W.H. Organization, (Editor) Genova 267

2. Snyder GL (2015) Functional profile of a novel modulator of serotonin, dopamine and glutamate neurotransmission. Psychopharmacology (Berl) 232: 605-21.

3. Gajic GM (2013) Group art therapy as adjunct therapy for the treatment of schizophrenic patients in day hospital. Vojnosanit Pregl 70: 1065-9.

4. Stefansson $\mathrm{H}$ (2002) Neuregulin 1 and susceptibility to schizophrenia. Am J Hum Genet 71: 877-92. 
Citation: Hernandez-Yánez HD, Reyes-Tovilla JE, Juárez-Rojop IE, González-Castro TB, Villar-Soto M, et al. (2015) Family Support and Adherence to Treatment in Patients Diagnosed with Schizophrenia in Tabasco, Mexico: A Case- Series Study. J Psychiatry 18: 304 doi: 10.4172/23785756.1000304

5. Messias EL, Chen CY, Eaton WW (2007) Epidemiology of schizophrenia: review of findings and myths. Psychiatr Clin North Am 30: 323-38.

6. Berta Moreno-Küstner CM (2014) José Almenara, Revisión crítica de las fuentes de variabilidad en la medición de la prevalencia de esquizofrenia. Salud Mental 37: $127-128$.

7. Díaz-Martínez A (2003) Mental health in a municipality of the State of Queretaro: a community-based psychiatric research model. Gac Méd Mex 139: 101-7.

8. Ciompi $\mathrm{L}(1980)$ The natural history of schizophrenia in the long term. $\mathrm{Br} J$ Psychiatry 136: 413-20.

9. Niemi LT (2003) Childhood developmental abnormalities in schizophrenia: evidence from high-risk studies. Schizophr Res 60: 239-58.

10. Davies G (2003) A systematic review and meta-analysis of Northern Hemisphere season of birth studies in schizophrenia. Schizophr Bull 29: 587-93.

11. Torrey EF (1997) Seasonality of births in schizophrenia and bipolar disorder: a review of the literature. Schizophr Res 28: 1-38.

12. Giusti-Rodriguez P, Sullivan PF (2013) The genomics of schizophrenia: update and implications. J Clin Invest 123: 4557-63.

13. Harrison PJ (2015) Recent genetic findings in schizophrenia and their therapeutic relevance. J Psychopharmacol 29: 85-96.

14. Tovilla-Zarate CA (2014) Association study between the MDR1 gene and clinical characteristics in schizophrenia. Rev Bras Psiquiatr.

15. Harrison PJ, Law AJ (2006) Neuregulin 1 and schizophrenia: genetics, gene expression, and neurobiology. Biol Psychiatry 60: 132-40.

16. Yin DM (2013) Reversal of behavioral deficits and synaptic dysfunction in mice overexpressing neuregulin 1. Neuron 78: 644-57.

17. Pato MT (2013) The genomic psychiatry cohort: partners in discovery. Am J Med Genet B Neuropsychiatr Genet 162b: 306-12.

18. American Psychiatric Association A. American Psychiatric, and D.-I. Task Force on, Diagnostic and statistical manual of mental disorders : DSM-IV-TR 2000, Washington, DC: American Psychiatric Association.

19. Ruby E (2014) Pathways associating childhood trauma to the neurobiology of schizophrenia. Front Psychol Behav Sci 3: 1-17.
20. Jakhar K (2015) A cross sectional study of prevalence and correlates of current and past risks in schizophrenia. Asian J Psychiatr.

21. Schmitt A (2014) The impact of environmental factors in severe psychiatric disorders. Front Neurosci 8: 19.

22. Hutchinson G, Haasen C (2004) Migration and schizophrenia: the challenges for European psychiatry and implications for the future. Soc Psychiatry Psychiatr Epidemiol 39: 350-7.

23. European Network of National Networks studying Gene-Environment Interactions In: Schizophrenia, Identifying gene-environment interactions in schizophrenia: contemporary challenges for integrated, large-scale investigations. Schizophr Bull 2014. 40: 729-36.

24. Misiak B, Kiejna A, Frydecka D (2015) The history of childhood trauma is associated with lipid disturbances and blood pressure in adult first-episode schizophrenia patients. Gen Hosp Psychiatry.

25. Sendt KV, Tracy DK, Bhattacharyya S (2015) A systematic review of factors influencing adherence to antipsychotic medication in schizophrenia-spectrum disorders. Psychiatry Res 225: 14-30.

26. Lieberman JA (2005) Effectiveness of antipsychotic drugs in patients with chronic schizophrenia. N Engl J Med 353: 1209-23.

27. Tseng PT (2014) The metabolic syndrome and risk of coronary artery disease in patients with chronic schizophrenia or schizoaffective disorder in a chronic mental institute. Kaohsiung J Med Sci 30: 579-86.

28. Tamrakar SM (2006) An open, randomized, comparative study of efficacy and safety of risperidone and haloperidol in schizophrenia. Kathmandu Univ Med J (KUMJ) 4: 152-60.

29. Divac N (2014) Second-generation antipsychotics and extrapyramidal adverse effects. Biomed Res Int 656370.

30. Khanna P (2014) Aripiprazole versus other atypical antipsychotics for schizophrenia. Cochrane Database Syst Rev 1: Cd006569.

31. Asmal $L$ (2013) Towards a treatment model for family therapy for schizophrenia in an urban African setting: Results from a qualitative study. Int J Soc Psychiatry 60: $315-320$

32. Sariah AE, Outwater AH, Malima KI (2014) Risk and protective factors for relapse among individuals with schizophrenia: a qualitative study in Dar es Salaam, Tanzania. BMC Psychiatry 14: 240. 